\title{
DNA-hexadecyltrimethyl ammonium chloride complex with enhanced thermostability as promising electronic and optoelectronic material
}

\author{
Jacek Niziot $^{1} \cdot$ Joanna Fiedor $^{1} \cdot$ Joanna Pagacz $^{2} \cdot$ Edyta Hebda $^{3} \cdot$ Monika Marzec $^{4}$. \\ Ewa Gondek ${ }^{5}$ I. V. Kityk ${ }^{6}$
}

Received: 13 July 2016/ Accepted: 8 August 2016/Published online: 20 August 2016

(C) The Author(s) 2016. This article is published with open access at Springerlink.com

\begin{abstract}
Recently DNA with hexadecyltrimethyl ammonium chloride (CTMA) complex has been included in some organic electronic devices. Thermal stability is one of key parameters required for successful applications in different electronic and optoelectronic devices. This work shows a possibility of enhancing thermal stability in this complexes and analyzes origin of this enhancement. Different techniques were applied to explore this issue of solid DNACTMA. Results of TGA analysis, DSC calorimetry, FTIR spectroscopy, and analysis of evolved gaseous products convince that chemical composition of DNA-CTMA complex remains fixed at temperatures $<200-220{ }^{\circ} \mathrm{C}$. In contrast, broadband dielectric spectroscopy applied to freshly prepared thin films of DNA-CTMA revealed at $150-160^{\circ} \mathrm{C}$ a permanent and irreversible change of dielectric properties. This phenomenon may be attributed to a transformation affecting the microstructure. Some
\end{abstract}

Jacek Nizioł

niziol@agh.edu.pl

1 Faculty of Physics and Applied Computer Science, AGH University of Science and Technology, al. Mickiewicza 30, 30-059 Krakow, Poland

2 Wroclaw Research Centre EIT+, ul. Stablowicka 147, 54-066 Wrocław, Poland

3 Department of Chemistry and Technology of Polymers, Cracow Technical University, ul. Warszawska 24, 31-155 Krakow, Poland

4 Institute of Physics, Jagiellonian University, ul. Łojasiewicza 11, 30-348 Krakow, Poland

5 Institute of Physics, Cracow University of Technology, ul. Podchorążych 1, 30-054 Krakow, Poland

6 Faculty of Electrical Engineering, Czestochowa University Technology, Armii Krajowej 17, 42201 Czestochowa, Poland experiments were conducted also for the native DNA as a reference. We demonstrate that DNA-CTMA complex chemical composition is more stable at temperatures about $200{ }^{\circ} \mathrm{C}$ with respect to DNA which is very important for laser operated optoelectronic applications.

\section{Introduction}

During the past decade biomaterials and their derivatives applied in solid filmform, began to be considered as promising electronic and optoelectronic material [1]. Particular interest presents DNA as promising materials for biodegradable electronics. It was just demonstrated a significant number of working devices possessing DNA or its derivatives and other organic chemicals. For example owing to a rare combination of HOMO and LUMO energy positions, this biopolymer can be used as an effective electron blocker. A thin layer of DNA derivative introduced in the structure of an of an organic light emitting diode (OLED) has enhanced significantly its performance [1-3]. High dielectric constant combined with low electronic conductivity make DNA an interesting material for organic field effect transistors [4, 5]. Different dyes can be particularly efficiently intercalated and spatially separated in DNA matrix, what is of enormous interest for nonlinear optics [6-8], lasers technology [9-11] and electrochromic devices [12].

The majority of devices classified as "organic electronics" consist of a series of "thin" films, with thickness varying within $10 \ldots 100 \mathrm{~nm}$. The majority of standard techniques that transform polymeric materials in thin films are based on solvents, like spin-coating, dip coating, Dr. Blade or ink-jet printing. Biological functions of the native DNA limit the number of available solvents to water only. 
In order to use more volatile solvents, DNA needs to be converted in complex with an amphiphilic lipid, which plays the role of surfactant. Such a complex dissolves in a range of alcohols and some chlorinated solvents. In revenge it is insoluble in water, but even "well" dried specimens of DNA or its complexes contains some residual structural water, impossible to be removed [13-16].

Properties of an electronic or a photonic device should be environmentally stable. This stability is determined by the stability of each of constituents. Generally polymeric materials are affected by environmental factors more intensively than inorganic compounds. Different aspects of DNA properties have been extensively studied during the past 60 years. These studies were carried out in aqueous environment due to interest of biological functions of DNA. However, there exist objective premises suggesting differences between properties of the native DNA in the solid and in aqueous solution, particularly when DNA is in complex with amphiphilic lipids.

Temperature is a key parameter for the stability of DNA properties. For example in water, upon heating, DNA double helix splits into single strands, what is referred to as melting [17]. An increased temperature may be the source of DNA decomposition, as it was found for example in the case of DNA in bone material [18]. The thermal decomposition depends on different factors and is not instantaneous. Heating makes the part of different protocols used for construction of many DNA consisting devices. Though, the question of DNA thermal stability is usually neglected. Usually discussion it is limited to a declaration that DNA thermal stability is superior to commercially available polymers like for example poly(methyl methacrylate) (PMMA). The source of such opinion arises from results obtained by standard polymer testing methods, like thermogravimetric analysis (TGA) or differential scanning calorimetry (DSC) [8, 19]. Commonly, the thermal stability is referred to the temperature, at which occurs loss of the mass other than entrapped solvent release. This temperature, situated between 200 and $220{ }^{\circ} \mathrm{C}$, was found practically independent on surfactant type and its content in the material.

Excessive heating may occur also in other experiments. For example, high power laser light is absorbed and transferred to the bulk as the heat in experiments with DNA/dye composites studied for potentially occurring nonlinear optical phenomena. Therefore, processes related to thermal annealing of DNA need to be well understand. It should be emphasized that relatively low photo-thermal stability is main restraining factor to apply them in optoelectronic devices with high power laser pulses.

In this work a range of complementary techniques were applied to describe quantitatively thermal annealing of the complex of DNA and hexadecyltrimethyl ammonium chloride (CTMA). So far, this complex may be considered as a standard in the field of DNA containing organic optoelectronics. Selected experiments were conducted also for the native DNA as reference.

\section{Materials and methods}

\subsection{Nucleic acids and chemicals}

DNA extracted from salmon roe and milt sacs, was purchased from Chitose Institute of Science and Technology (CIST) in Hokkaido, Japan. The exact details of purification technique applied at mass scale isolation are proprietary. Purity claimed by the supplier was c.a. $96 \%$ with a protein content of c.a. $2 \%$. In an earlier study we found also traces of 3d-metals [14]. The CIST-DNA has been the subject of many works on DNA based electronics [20] and so far can be considered as a standard material in this domain. According to many authors the average molecular weight of the CIST-DNA is centered at $8 \mathrm{MDa}$ [21]. However, our tests by agarose gel electrophoresis revealed broad bands, structureless and without a detectable maximum. Consequently, "a few MDa" seems to be the most reliable estimate for polydispersed molecular weight of the CIST-DNA. All the other chemicals [n-Butanol, analytical grade and cetyltrimethylammonium chloride ( $\geq 98 \%)$ ] were supplied by Sigma-Aldrich and used as received. Throughout this work only Millipore water was used.

\subsection{Synthesis of the DNA complex}

DNA was dissolved in water $\left(1.5 \mathrm{~g}\right.$ to $\left.250 \mathrm{ml} \mathrm{H}_{2} \mathrm{O}\right)$ on magnetic stirrer. Visually clear solution was sonicated in an ultrasonic bath at room temperature for $10 \mathrm{~min}$. This procedure decreased the molecular mass of DNA and the viscosity of the solution. It is believed that the cationic surfactant can easier access the surface of shorter DNA helices owing to limited tertiary structure adapted by the polymer. In result of sonication, DNA molecular weight was reduced to few hundred base pairs (as determined by agarose gel electrophoresis). It was verified that a longer sonication didn't further decrease molecular weight. Next, the solution was precipitated with aliquot of the surfactant CTMA solution, maintaining DNA to CTMA 1:1 wt. ratio. The precipitate was abundantly rinsed with water, dialyzed on $0.45 \mu \mathrm{m}$ PTFE filter and dried in a vacuum dryer.

\subsection{Preparation of samples}

DNA and DNA-CTMA powders were finely ground in agate mortar. Portions of both powders were re-dissolved at $10 \mathrm{wt} \%$ in Millipore water (DNA) and butanol (DNACTMA). After being filtered, the solutions were poured in 
PTFE moulds and let evaporate in the ambient air. The obtained films were c.a. $2 \mu \mathrm{m}$ thick and were separated from the substrate. All the samples, prior to measurements, were additionally dried in primary vacuum for $24 \mathrm{~h}$ at ambient temperature. If necessary, they were stored in air tight vials filled with argon and in presence of silica gel.

\subsection{Experimental techniques}

Thermally triggered mass loss was explored by thermogravimetric analysis (TGA) using Netzsch TG 209 apparatus. The samples were heated at constant rates in flux of argon or oxygen. The effect of the heating rate (varied between 5 and $20 \mathrm{~K} / \mathrm{min}$ ) was negligible. The first specimens of DNA and DNA-CTMA powders were heated from the ambient temperature up to $600{ }^{\circ} \mathrm{C}$. According to the obtained results, four temperatures $\left(190,230,270\right.$ and $\left.400{ }^{\circ} \mathrm{C}\right)$ were arbitrary chosen as "critical". Thereafter, the analytical runs was repeated with fresh specimens, but the heating was stopped at a one of these "critical" temperatures. The residues were carefully collected from the analytic pan, ground with $\mathrm{KBr}$ and pressed in pellets. Afterwards, infrared spectra were collected using Spectrum 65 Perkin Elmer FTIR spectrometer with spectral resolution $1 \mathrm{~cm}^{-1}$. A supplementary study was carried out through FTIR analysis of the gases released by the heated samples versus temperature. This type of measurements were performed using thermal analyzer STA F3 449 Jupiter Netzsch coupled to TENSOR 27 Bruker FTIR spectrometer.

Differential scanning calorimetry (DSC) scans were recorded employing DSC Mettler Toledo 822e calorimeter, the instrument that use two-furnace method. One of the furnaces was loaded with a sealed pan with the titled specimen, while the other with an empty sealed have been served as reference. In some cases, the lid of the DSC pan was punctured to let out vapors released during the heating. The sample and reference compartments were continuously purged with high-purity argon to prevent the sample from rehydration. Samples were heated and cooled cyclically few times. Starting from $25{ }^{\circ} \mathrm{C}$ the sample was heated at a constant ramp either (either 20, $10 \mathrm{~K} / \mathrm{min}$ or $\mathrm{K} / \mathrm{min}$ ) up to $190{ }^{\circ} \mathrm{C}$ and finally cooled down back to the initial temperature. Such cycles, consisting of two runs (heating and cooling), were repeated. In the further text, the runs will be referred by the cycle number.

Broadband dielectric spectroscopy (BDS) studies were carried out using a turn-key experimental setup (Companion 81, Novocontrol Technologies). Samples in form of thin films, were sandwiched between two round and freshly polished brass electrodes. Such a parallel plate capacitor was mounted in the instrument proprietary holder, BDS 1200 thermally stabilized in a cryostat (Novocool Cryosystem) by the flux of preheated gaseous nitrogen. The duration of a single scan across the whole frequency range $\left(10^{-1}-10^{6} \mathrm{~Hz}\right)$ was $2 \mathrm{~min}$. The sample temperature was
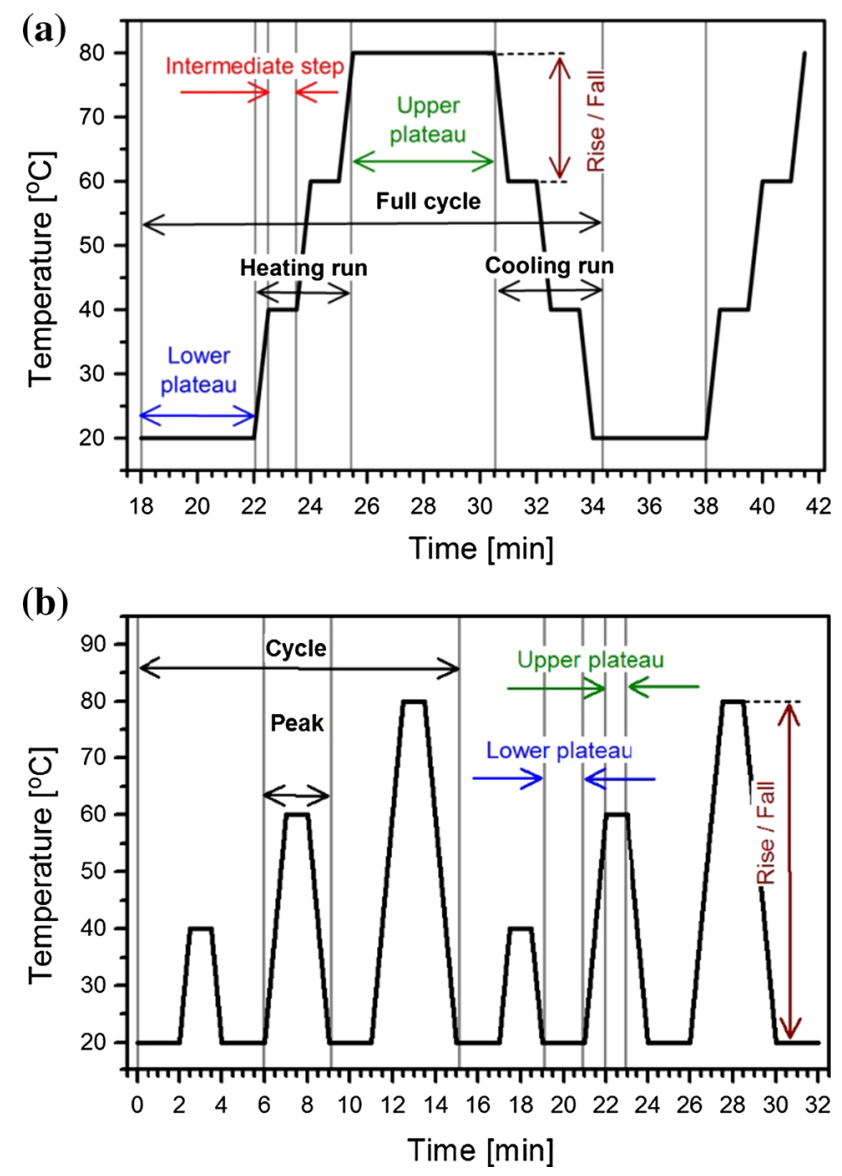

Fig. 1 Schematic diagrams of the heating programs and explanation of related terms used in the further text. a continuous heating program, b saw-teeth like program

varied as explained in the diagram shown in Fig. 1. Data provided by the BDS spectrometer are deduced from the sample capacity, that is measured directly. Quantitative analysis requires the actual value of the sample thickness. In the case of thin films prepared from DNA-surfactant complex was already demonstrated that the thickness varies in a complicated way in function of temperature [22]. For this reason, BDS data are presented in terms of the loss tangent, the parameter independent on the thickness.

Circular dichroism is considered as an ultimate evidence that DNA exists in the form of the double helix and not as a bunch of separated single strands. Circular dichroism spectra of thermally annealed DNA-CTMA samples were measured at room temperature on a JASCO J-815 (Japan) spectropolarimeter.

\section{Results and discussion}

TGA thermograms of DNA and DNA-CTMA obtained in argon (inert atmosphere) are presented in Fig. 2. For both materials an abrupt drop of the mass was observed in the vicinity of $220^{\circ} \mathrm{C}$. Usually, such a feature is caused by the 


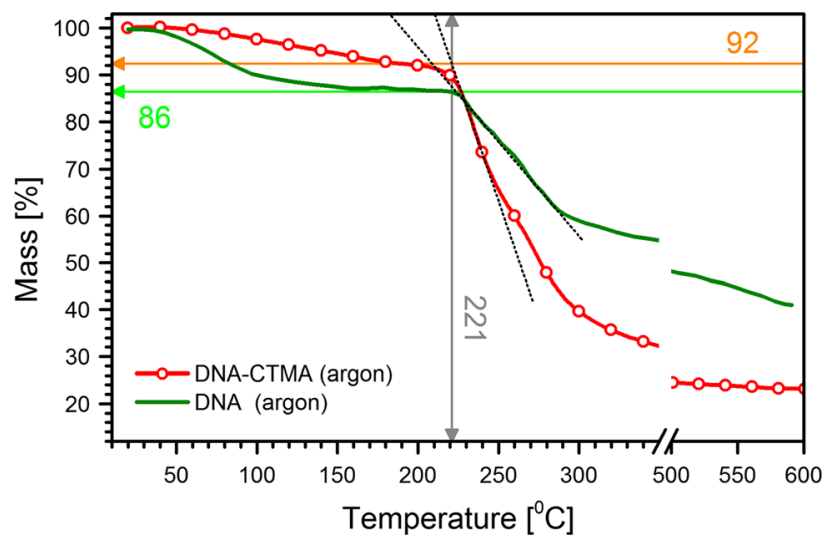

Fig. 2 TGA thermograms in argon atmosphere for DNA (full line) and DNA-CTMA (line with dots). The temperature of abrupt mass loss was deduced as the intersection of tangential lines

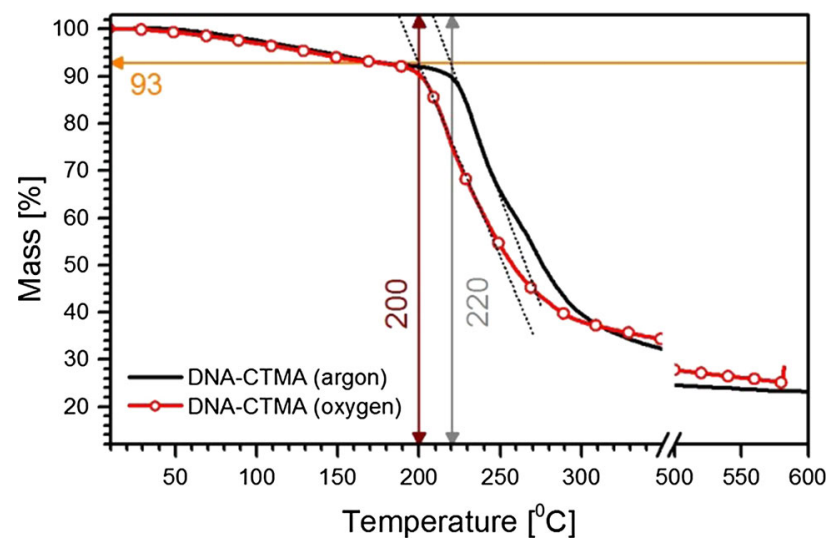

Fig. 3 TGA thermograms of DNA-CTMA measured in argon (full line) and oxygen (line with dots). The temperature of abrupt mass loss was found similarly as in Fig. 2

beginning of chemical decomposition. This threshold was preceded by a slow loss of the mass, what can be attributed to desorption of the residual solvent or the structural water. As can be seen, the mass lost before the chemical decomposition threshold was higher in the case of the native DNA. If the lost mass is identified as the residual water (the most intensive loss decrement at c.a $100{ }^{\circ} \mathrm{C}$ ), this observation can be explained by a much stronger affinity to water featured by the native DNA. If the purging gas (argon) is replaced with oxygen, the chemical decomposition threshold of DNA-CTMA complex decreases only by $20^{\circ} \mathrm{C}$ (Fig. 3).

Vibrational spectra of solid residues obtained after excessive heating to temperatures higher than the decomposition threshold are shown in Fig. 4. The pattern of initial DNA and DNA-CTMA spectra are very similar, except the small discrepancy observed between 1350 and $1550 \mathrm{~cm}^{-1}$, that can be explained as superposed vibrations of CTMA ionic amine head. Therefore, both spectra series can be interpreted in line with widely accepted assignments
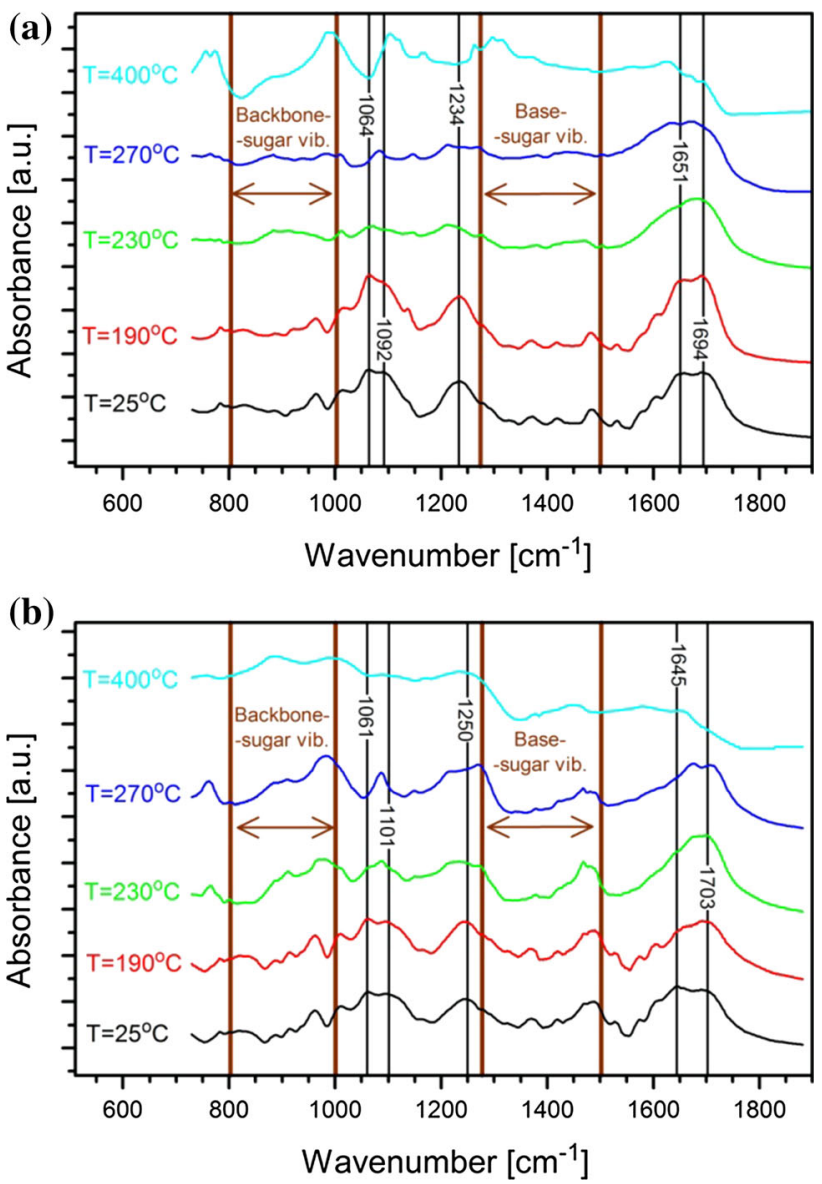

Fig. 4 FTIR spectra of samples residues obtained in result of heating up to "critical" temperatures (marked on the left side of each curve): a DNA, b DNA-CTMA. Vertical lines are drawn through characteristic peak maxima and labeled by wave numbers of the ambient temperature spectrum. To enhance readability the spectra magnitude was normalized and the corresponding background corrected. The wavenumber range was limited to clearly show bands, the most characteristic for DNA

for DNA [23-25]. The region within $1800-1500 \mathrm{~cm}^{-1}$, is very sensitive to hydration, base pairing and stacking interaction. The decrease of intensity at approximately $1700 \mathrm{~cm}^{-1}$ and simultaneous intensity increase observed at about $1650 \mathrm{~cm}^{-1}$ illustrate separation of the double-helix to single strands. The first of these bands is attributed to paired bases while the second is characteristic for separated bases. The $1500-1250 \mathrm{~cm}^{-1}$ spectral range consists of bands sensitive to glycosidic bond rotation, backbone conformation and sugar puckering modes. The absorption bands due to the symmetric and anti-symmetric stretching of the $\mathrm{PO}_{2}^{-}$are observed at c.a $1095 \mathrm{~cm}^{-1}$ and c.a $1240 \mathrm{~cm}^{-1}$, respectively. Backbone vibrations with strong contributions from a antisymmetric $\mathrm{C}-\mathrm{O}$ stretch appear at $1060 \mathrm{~cm}^{-1}$. Between 1000 and $800 \mathrm{~cm}^{-1}$ are present several bands corresponding to collective vibrations of the phosphodiester backbone and deoxyribose. 
An analysis of graphs in Fig. 4, leads to conclusion that chemical decomposition occurs as a multi-step process. A one thing different between spectra of samples heated at $25^{\circ} \mathrm{C}$ and at $190{ }^{\circ} \mathrm{C}$ is a slight increase of the band intensity at wavelength $1700 \mathrm{~cm}^{-1}$. Such a trend is reverse to that observed as result of dehydration [26]. It is surprising because an excessive dehydration is expected due to thermally forced removal of the structural water, inherently built in DNA structure.

More visible changes occur between spectra recorded at $190{ }^{\circ} \mathrm{C}$ and at $230{ }^{\circ} \mathrm{C}$. In DNA spectrum even bands characteristic of sugar and bases disappear. DNA-CTMA spectrum preserves some initial characteristics, but the intensity of c.a. $1060 \mathrm{~cm}^{-1}$ backbone vibrations is much decreased. Probably a fraction of the initial DNA-CTMA still preserves its structure. Spectra of the samples heated at $400{ }^{\circ} \mathrm{C}$ are featureless without any characteristics of DNA.

Vibrational spectra of gases exhaled by the sample during TGA analysis are shown in Fig. 5 in function of temperature. If an important decomposition process occurred at temperatures below $200{ }^{\circ} \mathrm{C}$ it would be the source of a combustion gas.

Indeed, volatile compounds other than water, were released not earlier than at temperatures exceeding $210{ }^{\circ} \mathrm{C}$ (DNA) and $217^{\circ} \mathrm{C}$ (DNA-CTMA). Starting with the ambient temperature, a series of close, narrow lines of water vapor can be seen in the FTIR spectra between 1300 and $2000 \mathrm{~cm}^{-1}$. A particularly sharp release of water vapor was observed between 70 and $140{ }^{\circ} \mathrm{C}$ with a maximum centered at $110^{\circ} \mathrm{C}$.

Differential scanning calorimetry (DSC) offers supplementary information on DNA thermodynamics. DSC of solid DNA has not often been reported. Available data appeared mainly in bibliography discussing hydration of DNA [27-31]. DSC of DNA-CTMA was reported even less frequently $[32,33]$. Interpretation and comparison between already published results (sometimes substantially different) is further complicated by the fact of different experimental procedures implemented by the authors. One of important issues, already pointed out [27], is gas-tightness of pans where the specimen resides during DSC experiment. Vapors is released from the sample condensate inside the pan when temperature returns to the ambient value. It is not evident that water can rehydrate DNA in such a manner that the initial state of the material would be recovered. In result, during the next heating cycle a biphasic system will be studied. The solution to this inconvenience is a not hermetic pan. In such a case all vapors are removed during the first heating run by the inert gas purging the heating compartment. In this study lids of DSC pans were punctured to make them non-hermetic.

During the first heating run, in the recorded thermograms were observed broad and smoothly edged structures
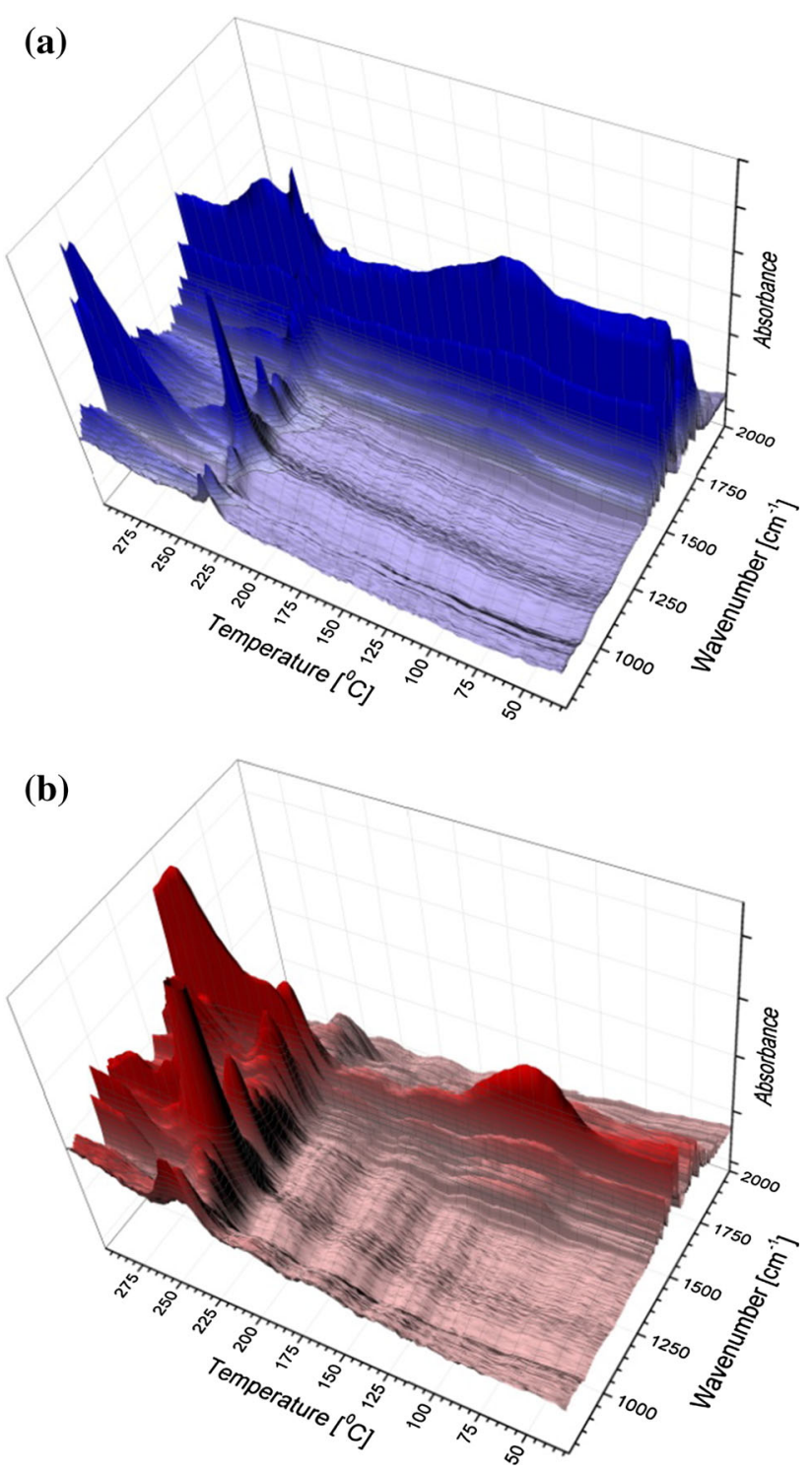

Fig. 5 FTIR spectra of the gases evolved during TGA analysis. a DNA, b DNA-CTMA

as shown in Fig. 6. The most intense heat flow appeared in the vicinity of $100{ }^{\circ} \mathrm{C}$, what evidently indicates the release of water. Next part of the data illustrating the first cooling and the second heating runs are in Fig. 7. These patterns are substantially different than in the case of the first heating run. Cooling and heating of DNA both are represented by featureless, inclined straight lines. Analogous graphs of DNA-CTMA in Fig. 7 have a smooth step, typical of glass transition. The appropriate fragment of the graphs are enlarged in Fig. 8. Indeed, the region of glass transition defined by tangential lines, is situated between 80 and $119^{\circ} \mathrm{C}$. The glass transition temperature $\mathrm{T}_{\mathrm{g}}$ calculated as the middle of the above temperature range is equal to $99{ }^{\circ} \mathrm{C}$ regardless the direction of temperature variation (cooling or heating). In an earlier work [30] DSC 


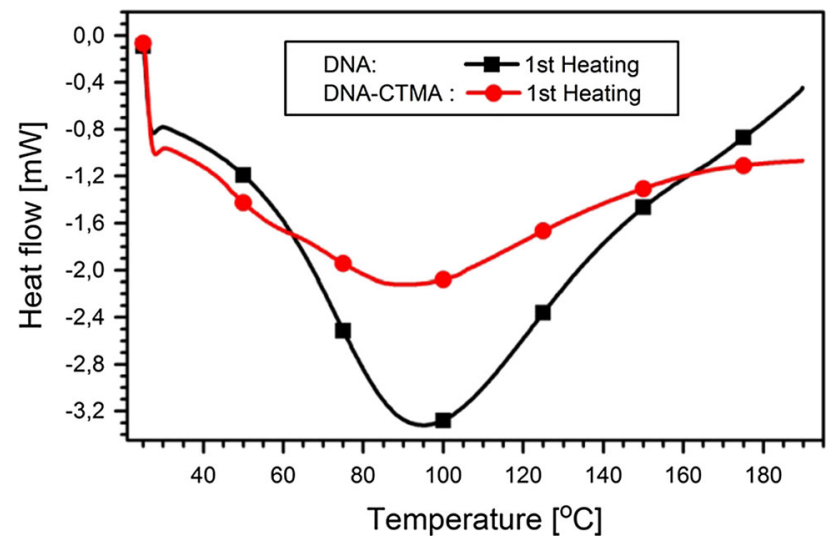

Fig. 6 DSC scans during first heating run at $10 \mathrm{~K} / \mathrm{min}$ for DNA and DNA-CTMA. Symbols are not experimental points, they serve to make a distinction between graphs

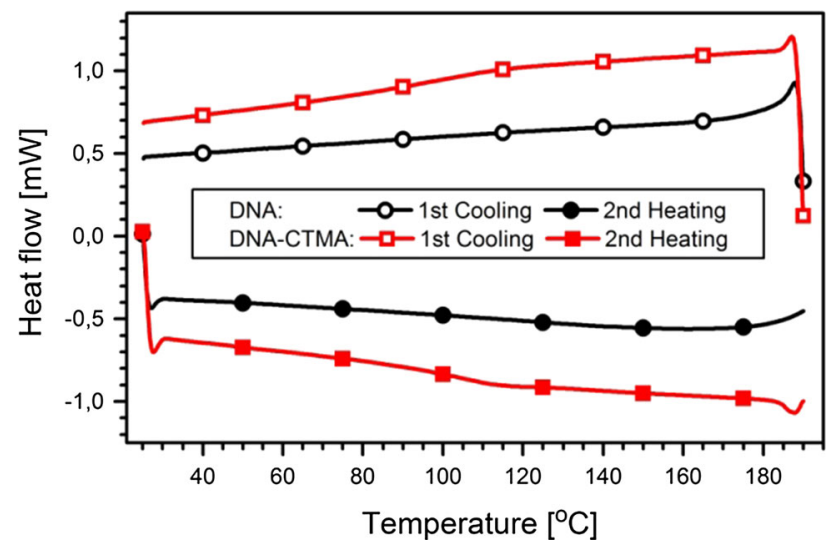

Fig. 7 DSC scans, the first cooling run and the second heating run, $10{ }^{\circ} \mathrm{C} / \mathrm{min}$, sealed pans with punctured lid. Symbols are not experimental points, they serve to make a distinction between graphs

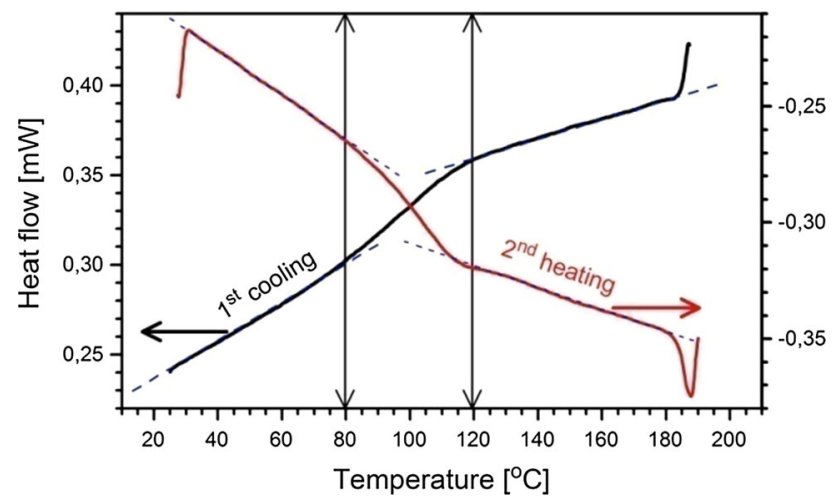

Fig. 8 DSC scans, the first cooling run and the second heating run, DNA-CTMA in sealed pans with punctured lid, $10^{\circ} \mathrm{C} / \mathrm{min}$, (same data as in Fig. 7, enlarged and rearranged). Double arrows indicate temperatures, where tangential lines deviate from graphs

experiment was carried out with DNA closed in hermetic pans revealed reversible glass transition, appearing as a smooth step on thermograms. The $T_{g}$ was shifted towards

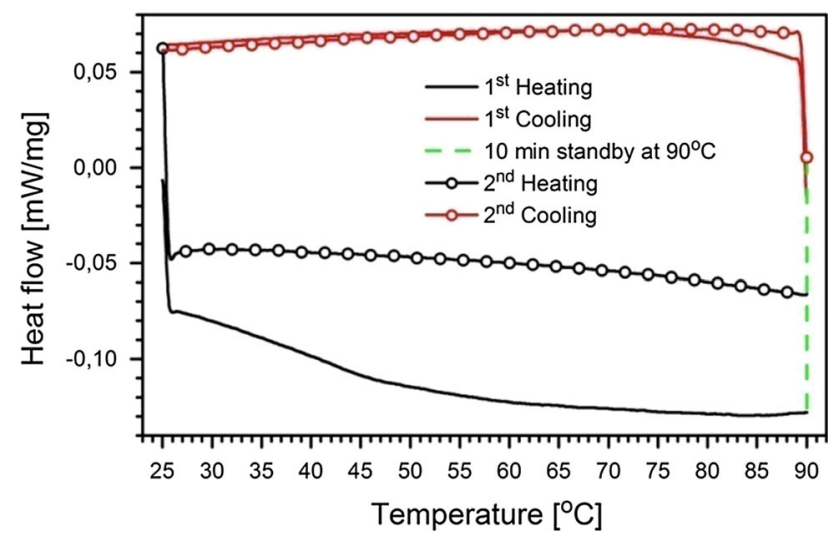

Fig. 9 DSC scans of DNA-CTMA, heating/cooling rates (sealed pans with punctured lid) at $2{ }^{\circ} \mathrm{C} / \mathrm{min}$ rate up to $90{ }^{\circ} \mathrm{C}$. Symbols are not experimental points, they serve to make a distinction between graphs. Similar results were obtained using a faster heating rate $-10^{\circ} \mathrm{C} / \mathrm{min}$

higher temperatures as hydration of the sample decreased. However, at an extremely low hydration (one water molecule per nucleotide) the characteristic step disappeared. This absence of glass transition is in agreement with DNA thermogram presented in Fig. 7, if one supposes that all water was removed from the sample during the first heating run.

The bound water may act as a natural plasticizer [34] in many biopolymers. The observed reproducibility of DNACTMA glass transition means that either some of the bound water remains confined despite heating up to $190{ }^{\circ} \mathrm{C}$ (what would be surprising) or CTMA plasticizes DNA (what is a more realistic explanation). The exact value of $T_{g}$ will be depend on many factors. Other authors situate $T_{g}$ of DNACTMA, found by DSC, at much higher temperatures, something like $150{ }^{\circ} \mathrm{C}$ [32]. However, in the last work precisions on details of the experiment are not explained.

In the available bibliography can be found "first run" DSC thermograms of solid DNA, that consist of visible singularities between 40 and $80{ }^{\circ} \mathrm{C}$ [27, 34]. These singularities were attributed to denaturation of DNA. In the current study such an observation was not reproduced. A DNA specimen was subjected to two heating/cooling cycles arranged between 25 and $90{ }^{\circ} \mathrm{C}$. Between the end of heating run and the beginning of cooling run, the sample was conditioned at $90{ }^{\circ} \mathrm{C}$ for $15 \mathrm{~min}$. The first heating run corresponds to an almost constantly inclined line with hardly visible onset at lower temperatures Fig. 9. The subsequent cooling/heating thermograms are linear and featureless. In other words, any temperature related phenomena do not occur in DNA-CTMA in this temperature range. This conclusion is consistent with result obtained for DNA-CTMA solution in butanol [32].

Usually raised temperature and related structural transitions in particular, release vibration modes of polymer 
fragments bearing dipolar moment. This phenomenon can by conveniently studied in alternating electric field of low frequencies by broadband dielectric spectroscopy (BDS). BDS follows variation of dielectric parameters versus temperature and frequency. Similarly to results obtained by previously discussed experimental techniques, BDS also evidences qualitative differences between spectra of DNACTMA films subjected to heating for the first time as in Fig. 10a and cooled back to the ambient temperature as in Fig. 10b. The pattern recorded during the first cooling run was preserved during subsequent heating/cooling cycles. The shape of the data demonstrated in Fig. 10 resembles a mountainous landscape. Patterns of the spectra recorded during the first heating run and all the other will be referenced to as A and B, respectively. Frequencies corresponding to points at the "ridge" define the maxima of the relaxation times distribution. The plot of relaxation times from the ridge is shown in Fig. 11 in inverse temperature and frequency coordinates. A closer inspection of these data, allow to identify two evidently different regions in the plot representing the first heating. At higher and lower temperatures the curve collapses with tangential lines. In the used coordinates, a linear function can be considered as arising from an Arrhenius-type dependence. In the case of the first heating run, tangential line extending towards low temperatures is almost horizontal (frequency is in logarithmic scale) as if the material was very stiff. The curve begins to rise and to deviate at temperatures slightly lower than $100{ }^{\circ} \mathrm{C}$. The function becomes again linear when temperature reaches $150^{\circ} \mathrm{C}$. Now it is much more inclined like in the case of viscoelastic, rubbery materials. In contrast, the curve corresponding to cooling is practically linear across the whole temperature range.

A logical description of the observed phenomenon must include rearrangement of the microstructure. The material, initially remains stiff and temperature practically does not affects its relaxation. After reaching $100{ }^{\circ} \mathrm{C}$ it becomes gradually viscoelastic and the maximum of relaxation moves towards higher frequencies. At the extreme end of the temperature range occurs a phase transition. In result, the material becomes more stiff, however not as stiff as it was initially at lower temperatures. This new structure persists despite consecutively repeated heating/cooling cycles.

The kinetics of the observed phenomenon was supposed to be dependent on a particular heating program used during BDS measurements. In order to further investigate this issue, a new thermal "comb-like" program was implemented. The "comb-line" pattern, consisting of temperature "spikes" (high temperature applied for a short period) is explained in Fig. 1b. Fresh samples of DNACTMA were subjects of a series of similar BDS experiments. The heating program consisting of temperature
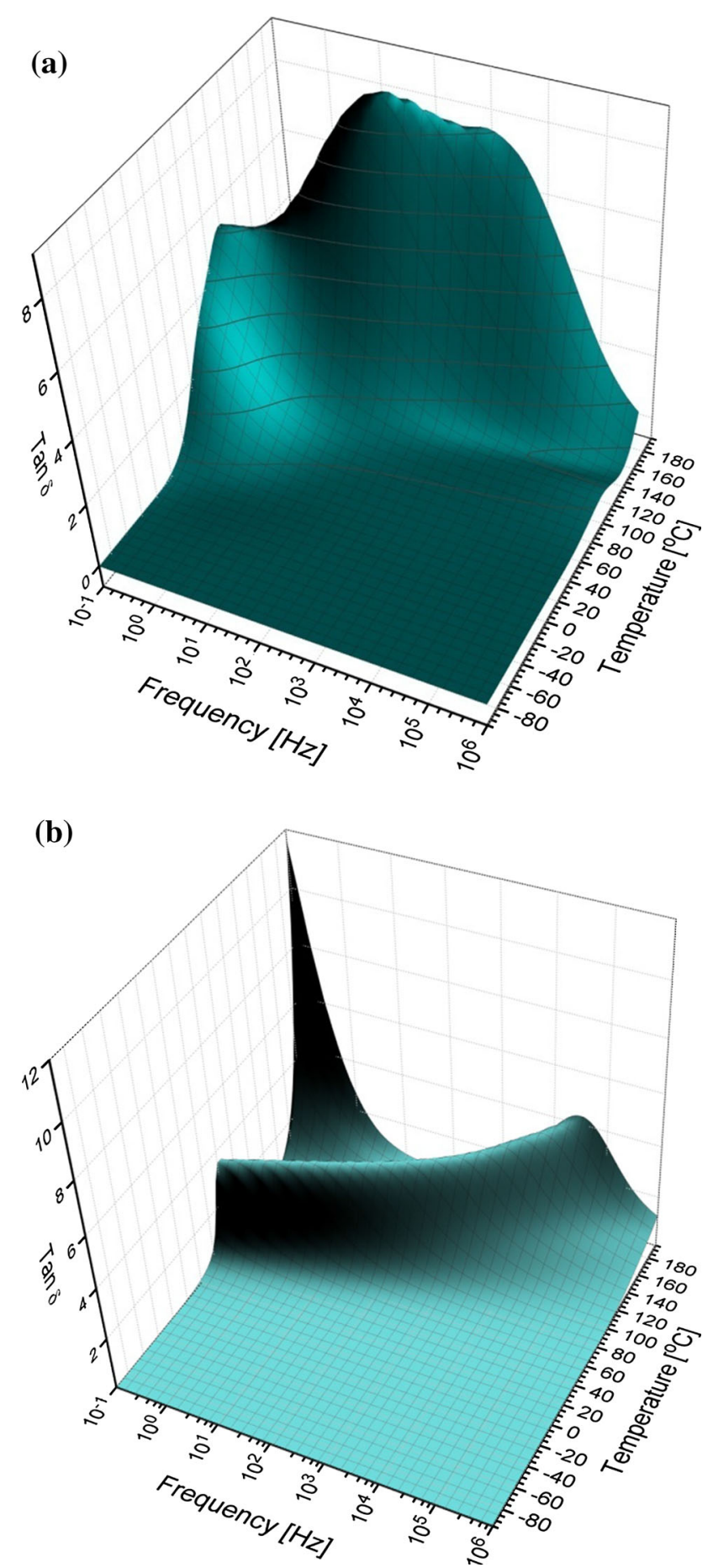

Fig. 10 DNA-CTMA, 3D plot of BDS spectrum a first heating run, b first cooling. Temperature during the experiment was varied according to the scheme from Fig. 1a between -95 and $190{ }^{\circ} \mathrm{C}$ with the following parameters: rise/fall temperature step $-5{ }^{\circ} \mathrm{C}$, rise/fall temperature rate $5 \mathrm{~K} / \mathrm{min}$, intermediate step delay $-5 \mathrm{~min}$, upper and lower plateau $5 \mathrm{~min}$

"spikes" was modified and the duration of upper/lower temperature plateau was extended. Data obtained for programs consisting of relatively short temperature "spikes" demonstrated entire reversibility of dielectric properties of 


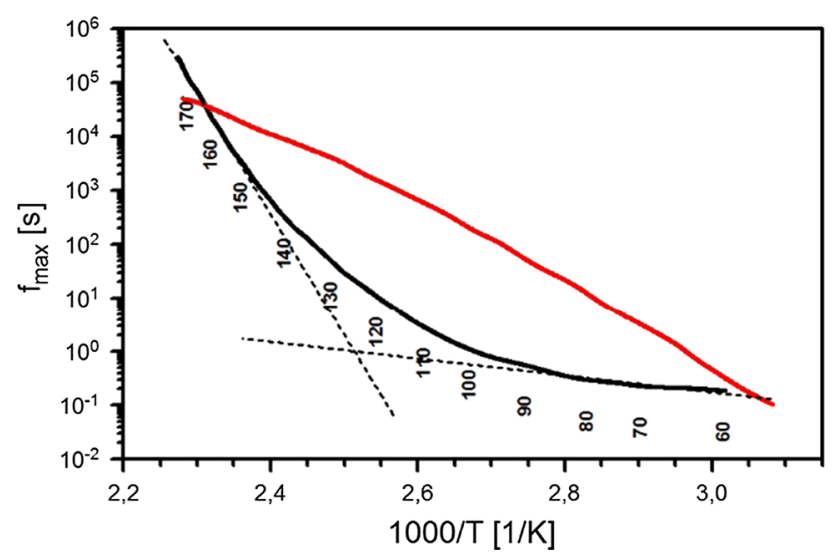

Fig. 11 DNA-CTMA, trace of the "ridges" from Fig. 10a (lower, black curve) and Fig. 10b (upper, red curve), plotted in inverse temperature and frequency coordinates (Color figure online)

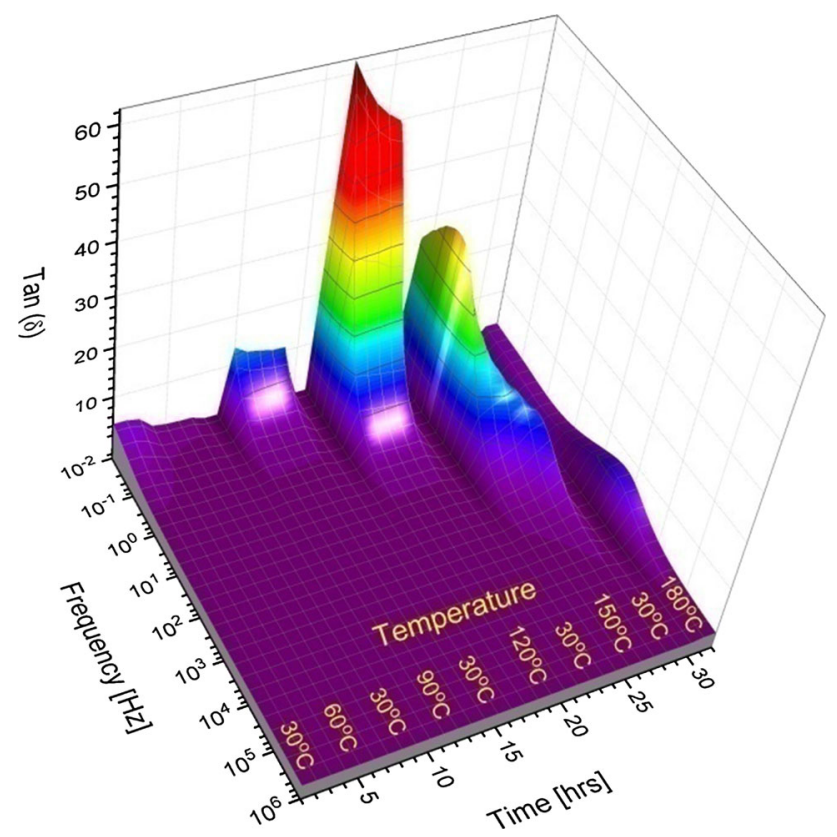

Fig. 12 BDS spectra of a single DNA-CTMA thin film recorded during heating cycle, profiled as in Fig. 1b. The height of temperature peaks was subsequently increased by $30{ }^{\circ} \mathrm{C}$ from 30 to $180{ }^{\circ} \mathrm{C}$, upper/ lower plateau equal to $4 \mathrm{~h}$, rise/fall rate $10 \mathrm{~K} / \mathrm{min}$, spectra recorded at the upper and the lower temperature plateau every $30 \mathrm{~min}$

the DNA-CTMA films heated below $160{ }^{\circ} \mathrm{C}$. Basically, after each temperature "spike", the material returned to its initial state as seen by BDS. Results of the ultimate example of such experiment (with the longest duration of each temperature step) is shown in Fig. 12. Like previously, at temperatures inferior to $150{ }^{\circ} \mathrm{C}$ temporal stability of the BDS spectrum was preserved, regardless a small decrease at extremely low frequencies (a phenomenon usually ascribed to electrode polarization). At $150{ }^{\circ} \mathrm{C}$, the general behavior changed. Within $2 \mathrm{~h}$ of continuous heating, the maximum of the BDS spectrum progressively

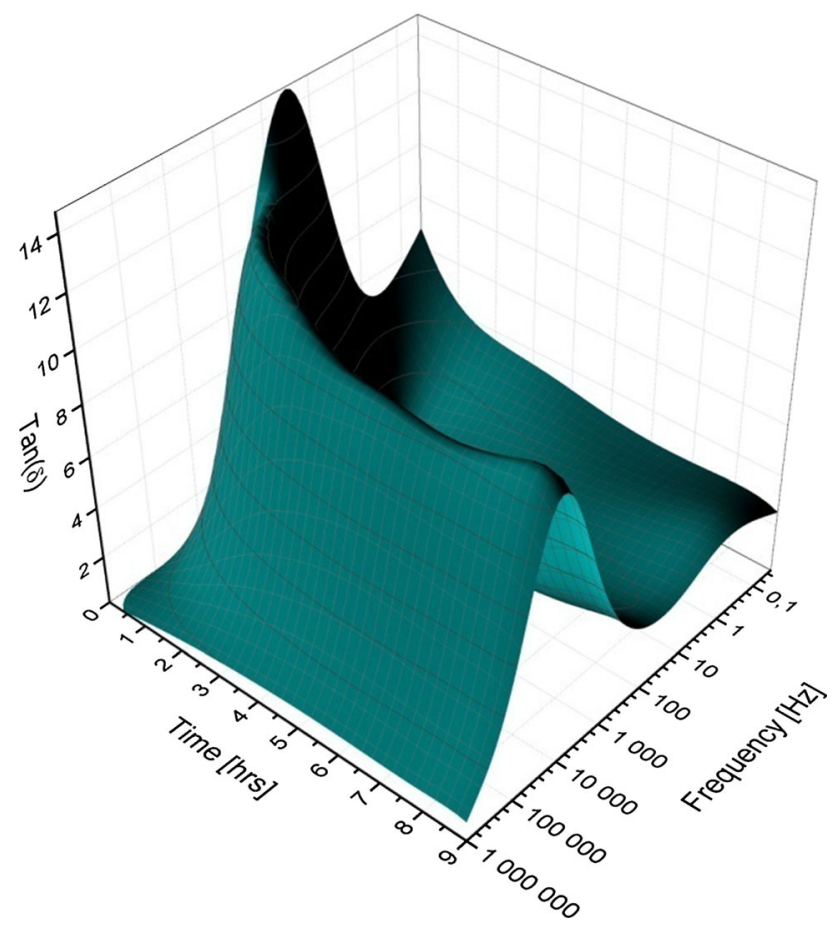

Fig. 13 BDS spectrum of DNA-CTMA thin film recorded at $160^{\circ} \mathrm{C}$, during $9 \mathrm{~h}$

shifted from low frequencies to some kHz. At $180{ }^{\circ} \mathrm{C}$ this transition occurred too fast to be recorded by the experimental setup. An additional experiment, where a fresh sample was annealed at $160{ }^{\circ} \mathrm{C}$, revealed such a transition already after $30 \mathrm{~min}$ from the beginning. The new pattern was stable and remained unchanged for next $9 \mathrm{~h}$ of heating (Fig. 13). The results provided by BDS spectroscopy ascertain the existence of a temperature, located between 150 and $160{ }^{\circ} \mathrm{C}$, that is critical to DNA-CTMA. If this material is subjected to the critical or to a higher temperature its dielectric characteristics are irreversibly changed. The value of the critical temperature corresponds to the one limiting molecular mass stability [35].

Although an excessive heating is destructive for the molecular mass of DNA and DNA-CTMA, there exists some indirect evidences suggesting that only the helix length is shortened. Smaller fragments were effectively intercalated with ethidium bromide and strong fluorescence was observed [35]. The last phenomenon is specific for double helix of DNA. A more direct method which allows to identify the double helix. Its optical activity is manifested through circular dichroism (CD). The shape of CD spectra is routinely used to identify the form adopted by DNA helix. A series of thin films prepared from DNACTMA were thermally equilibrated for $10 \mathrm{~min}$ on a heating plate. CD spectra measured afterwards are shown in Fig. 14. They can be discussed only quantitatively, because a common constrains resulting from deterioration of the 


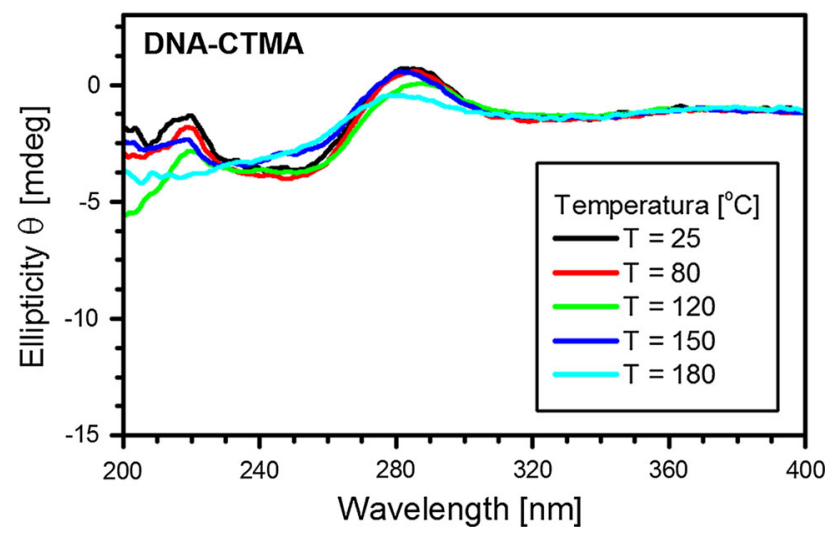

Fig. 14 Circular dichroism spectroscopy. A series of thermally annealed thin DNA-CTMA films

film surface quality due to the heating. The sample surface becomes rough and a portion of the probing light is dispersed.

Nevertheless, inspection of the graphs in Fig. 14 shows, that the $\mathrm{CD}$ spectra preserved their overall shape at temperatures as high as at least $180^{\circ} \mathrm{C}$.

The obtained enhancement of the thermo stability may do these materials comparable with other organic chromohores [36, 37] as well as inorganic nanocomposites [38].

\section{Conclusion}

We have established that DNA-CTMA complex chemical composition is more stable at temperatures about $200{ }^{\circ} \mathrm{C}$ with respect to traditional ones which is very important for laser operated optoelectronics applications. Such novel material preserves its dielectric properties regardless further heating what may additionally confirm their enhanced thermal stability. The DNA-CTMA complex which initially is insensitive to temperature, at $150-160{ }^{\circ} \mathrm{C}$ permanently changes its dielectric properties. The most probable explanation is a new microstructure adapted by the material. The observed reproducibility of DNA-CTMA glass transition means that either some of the bound water remains confined despite heating up to $190{ }^{\circ} \mathrm{C}$ (what would be surprising) or CTMA plasticizes the DNA (what is a more realistic explanation). The $\mathrm{T}_{\mathrm{g}}$ is shifted towards higher temperatures as hydration of the sample decreased. However, at an extremely low hydration (one water molecule per nucleotide) the characteristic step is disappeared. This absence of glass transition is in agreement with DNA thermogram if one suppose that all water was removed from the sample during the first heating run. The previous research have shown the "first run" DSC thermograms of solid DNA, that contain visible singularities between 40 and $80{ }^{\circ} \mathrm{C}$. These singularities were attributed to denaturation of DNA. In the current study such facts were not reproduced. A DNA specimen was subjected to two heating/cooling cycles situated between 25 and $90{ }^{\circ} \mathrm{C}$. Between the end of heating run and the beginning of cooling run, the sample was conditioned at $90{ }^{\circ} \mathrm{C}$ for $15 \mathrm{~min}$. Generally in this temperature range it was absent in this case. The general description of the observed phenomenon must include rearrangement of the microstructure. The material, initially remains stiff and temperature practically does not affects its relaxation. After reaching $100{ }^{\circ} \mathrm{C}$ it becomes gradually viscoelastic and the maximum of relaxation moves towards higher frequencies. At the extreme end of the temperature range occurs a phase transition. In result, the material becomes more stiff, however not as stiff as it was initially at lower temperatures. This new structure persists despite consecutively repeated heating/cooling cycles.

Acknowledgments This project was partially financed by the Polish Ministry of Science and Higher Education. The research was carried out with the equipment purchased thanks to the financial support of the European Regional Development Fund in the framework of the Polish Innovation Economy Operational Program (Contract No. POIG.02.01.00-12-023/08).

Open Access This article is distributed under the terms of the Creative Commons Attribution 4.0 International License (http://crea tivecommons.org/licenses/by/4.0/), which permits unrestricted use, distribution, and reproduction in any medium, provided you give appropriate credit to the original author(s) and the source, provide a link to the Creative Commons license, and indicate if changes were made.

\section{References}

1. B. Sun, D. Liang, X. Li, P. Chen, J. Mater. Sci.: Mater. Electron. 27, 3957-3962 (2016)

2. R. Grykien, B. Luszczynska, I. Glowacki, J. Ulanski, F. Kajzar, R. Zgarian, I. Rau, Opt. Mater. 36, 1027-1033 (2014)

3. I.C. Chen, Y.W. Chiu, Y.C. Hung, Jpn. J. Appl. Phys. 51, 031601 (2012)

4. C. Yumusak, T.B. Singh, N.S. Sariciftci, J.G. Grote, Appl. Phys. Lett. 95, 263304 (2009)

5. F. Ouchen, N. Venkat, D.M. Joyce, K.M. Singh, S.R. Smith, P.P. Yaney, E.M. Heckman, C.M. Bartsch, J.G. Grote, Appl. Phys. Lett. 103, 113701 (2013)

6. B. Sahraoui, M. Pranaitis, D. Gindre, J. Niziol, V. Kazukauskas, J. Appl. Phys. 110, 083117 (2011)

7. I. Rau, J.G. Grote, F. Kajzar, A. Pawlicka, Comptes Rendus Phys. 13, 853-864 (2012)

8. F. Ouchen, E. Gomez, D. Joyce, A. Williams, S. Kim, E. Heckman, L. Johnson, P. Yaney, N. Venkat, A. Steckl, F. Kajzar, I. Rau, A. Pawlicka, P. Prasad, J. Grote, Proc. SPIE 8983, 89831A (2014)

9. L. Sznitko, K. Parafiniuk, A. Miniewicz, I. Rau, F. Kajzar, J. Niziol, E. Hebda, J. Pielichowski, B. Sahraoui, J. Mysliwiec, Opt. Mater. 35, 2389-2393 (2013)

10. Y. Kawabe, L. Wang, T. Nakamura, N. Ogata, Appl. Phys. Lett. 81, 1372-1374 (2002)

11. T. Suzuki, Y. Kawabe, Opt. Mater. Express 4, 1411-1419 (2014) 
12. A. Pawlicka, F. Sentanin, A. Firmino, J.G. Grote, F. Kajzar, I. Rau, Synth. Met. 161, 2329-2334 (2011)

13. J. Nizioł, P. Nowak, J. Kobierski, H. Harańczyk, Eur. Polymer J. 66, 301-306 (2015)

14. J. Nizioł, H. Harańczyk, J. Kobierski, E. Hebda, J. Pielichowski, B. Ostachowicz, J. Appl. Phys. 114, 144701 (2013)

15. H. Haranczyk, J. Kobierski, J. Niziol, E. Hebda, J. Pielichowski, D. Zalitacz, M. Marzec, A. El-Ghayoury, J. Appl. Phys. 113, 044702 (2013)

16. H. Haranczyk, J. Kobierski, D. Zalitacz, P. Nowak, A. Romanowicz, M. Marzec, J. Niziol, E. Hebda, J. Pielichowski, Acta Phys. Pol. A 121, 485-490 (2012)

17. W. Saenger, Principles of Nucleic Acid Structure, 1st edn. (Springer, New York, 1984)

18. J.D. Fredericks, P. Bennett, A. Williams, K.D. Rogers, Forensic Sci. Int.: Genet. 6, 375-380 (2012)

19. E.M. Heckman, R.S. Aga, E.M. FehrmanCory, F. Ouchen, A. Lesko, B. Telek, J. Lombardi, C.M. Bartsch, J.G. Grote, Proc SPIE 8464, 84640P (2012)

20. J.-I. Jin, J. Grote, Materials Science of DNA, 1st edn. (CRC Press, Boca Raton, 2011)

21. E.M. Heckman, J.A. Hagen, P.P. Yaney, J.G. Grote, F.K. Hopkins, Appl. Phys. Lett. 87, 211115 (2005)

22. J. Nizioł, J. Appl. Phys. 116, 234701 (2014)

23. V.V. Andrushchenko, S.V. Kornilova, L.E. Kapinos, E.V. Hackl, V.L. Galkin, D.N. Grigoriev, Y.P. Blagoi, J. Mol. Struct. 408-409, 225-228 (1997)

24. M. Banyay, M. Sarkar, A. Gräslund, Biophys. Chem. 104, 477-488 (2003)

25. H. Matsui, N. Toyota, M. Nagatori, H. Sakamoto, K. Mizoguchi, Phys. Rev. B 79, 235201 (2009)
26. B. Zhu, T. Furuki, T. Okuda, M. Sakurai, J. Phys. Chem. B 111, 5542-5544 (2007)

27. R.L. Marlowe, A.M. Lukan, S.A. Lee, L. Anthony, R. Chandrasekaran, A. Rupprecht, J. Biomol. Struct. Dyn. 14, 373-379 (1996)

28. G.I. Tsereteli, T.V. Belopolskaya, N.A. Grunina, J. Therm. Anal. Calorim. 92, 711-716 (2008)

29. H.W. Hoyer, M. Chow, V. Gary, J. Colloid Interface Sci. 80, 132-135 (1981)

30. S.L. Lee, P.G. Debenedetti, J.R. Errington, B.A. Pethica, D.J. Moore, J. Phys. Chem. B 108, 3098-3106 (2004)

31. A. Wildes, N. Theodorakopoulos, J. Valle-Orero, S. CuestaLópez, J.L. Garden, M. Peyrard, Phys. Rev. E 83, 061923 (2011)

32. E.M. Heckman, C.M. Bartsch, P.P. Yaney, G. Subramanyam, F. Ouchen, J.G. Grote, in Materials Science of DNA, 1st edn., ed. by J.-I. Jin, J. Grote (CRC Press, Boca Raton, 2011), pp. 180-229

33. L.E. Johnson, L.N. Latimer, S.J. Benight, Z.H. Watanabe, D.L. Elder, B.H. Robinson, C.M. Bartsch, E.M. Heckman, G. Depotter, K. Clays, Proc. SPIE 8464, 1-10 (2012)

34. G.I. Tsereteli, T.V. Belopolskaya, N.A. Grunina, O.L. Vaveliouk, J. Therm. Anal. Calorim. 62, 89-99 (2000)

35. J. Nizioł, R. Ekiert, M. Śniechowski, M. Słomiany, M.M. Marzec, Opt. Mater. 56, 84-89 (2016)

36. F. Bures, H. Cermakova, J. Kulhanek, M. Ludwig, W. Kuznik, I.V. Kityk, T. Mikysek, A. Ruzicka, Eur. J. Organic Chem. 2012, 529-538 (2012)

37. T.S. Kolev, I.V. Kityk, J. Ebothe, B. Sahraoui, Chem. Phys. Lett. 443, 309-312 (2007)

38. A. Majchrowski, I.V. Kityk, J. Ebothe, Phys. Status Solidi, 241, 3047-3055 (2004) 